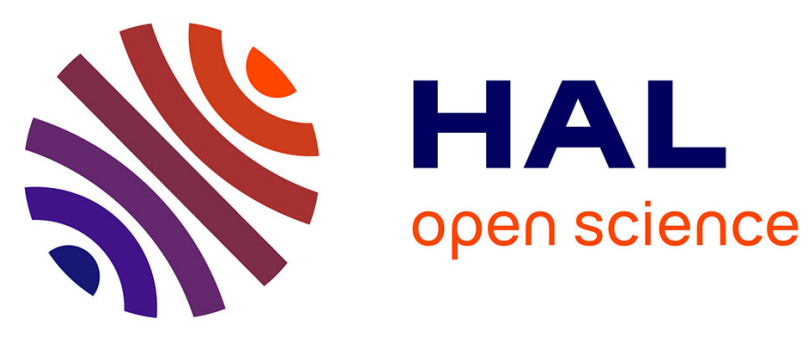

\title{
Lack of evidence for association of UQCRC1 with autosomal dominant Parkinson's disease in Caucasian families
}

Thomas Courtin, Christelle Tesson, Jean-Christophe Corvol, Suzanne Lesage, Alexis Brice

\section{To cite this version:}

Thomas Courtin, Christelle Tesson, Jean-Christophe Corvol, Suzanne Lesage, Alexis Brice. Lack of evidence for association of UQCRC1 with autosomal dominant Parkinson's disease in Caucasian families. neurogenetics, 2021, 10.1007/s10048-021-00647-4 . hal-03297026

\section{HAL Id: hal-03297026 \\ https://hal.sorbonne-universite.fr/hal-03297026}

Submitted on 23 Jul 2021

HAL is a multi-disciplinary open access archive for the deposit and dissemination of scientific research documents, whether they are published or not. The documents may come from teaching and research institutions in France or abroad, or from public or private research centers.
L'archive ouverte pluridisciplinaire HAL, est destinée au dépôt et à la diffusion de documents scientifiques de niveau recherche, publiés ou non, émanant des établissements d'enseignement et de recherche français ou étrangers, des laboratoires publics ou privés. 


\section{Lack of evidence for association of UQCRC1 with autosomal dominant Parkinson's disease in Caucasian families}

Authors: Thomas Courtin1,2, Christelle Tesson1, Jean-Christophe Corvol1,3, Suzanne Lesage1, Alexis Brice1,2 for the French Parkinson's disease genetics (PDG) group

1. Sorbonne Université, INSERM, CNRS, Institut du Cerveau - Paris Brain Institute - ICM, 75013, Paris, France

2. Hôpital Pitié-Salpêtrière, DMU BioGe'M, AP-HP, 75013, Paris, France

3. Hôpital Pitié-Salpêtrière, DMU Neuroscience, AP-HP, 75013, Paris, France

Lin et al. ${ }^{1}$ recently reported that rare ubiquinol-cytochrome c reductase core protein I (UQCRC1) variants are associated with autosomal dominant (AD) forms of parkinsonism and polyneuropathy. They first identified an heterozygous substitution (c.941A >C, p.Tyr314Ser RefSeq NM_003365.2) in the mitochondrial (UQCRC1) gene, which co-segregated with the disease within a large Taiwanese family with PD and polyneuropathy. Additional analysis of 699 unrelated PD probands with familial PD and 1934 sporadic PD patients revealed another two variants (c.931A>C, p.Ile311Leu and c.73_74insG, p.Ala25Glyfs*27) in UQCRC1 only in probands with familial PD but no overt polyneuropathy. All substitutions were absent in 1077 controls and in the Taiwan Biobank exome database of healthy participants $(n=1517$ exomes). Pathogenicity was reinforced by functional studies using CRISPR/Cas9-based knockin human dopaminergic cell lines, Drosophila and mouse models. Altogether, their genetic data combined with in vitro and in vivo studies supported the functional pathogenicity of rare UQCRC1 variants in familial parkinsonism with polyneuropathy. Given the autosomal dominant inheritance of UQCRC1 variants in Taiwanese families, we selected specific cases with dominant transmission from our large collection of PD families to identify rare variants in UQCRC1. This represents the first attempt to replicate these findings in AD PD Caucasian families, consistent with the original article's discovery cohort.

Our cohort of 3540 PD index cases included 1131 probands with inheritance compatible with autosomal dominant transmission (at least 2 affected in two generations). Among them 994 underwent targeted or whole exome sequencing revealing the disease-causing gene in 220 cases. Exome data from 163 families in which no known causative gene was identified was analysed in this study. This cohort consisted in 241 sampled PD patients (143 males, 60\% ; 98 
females, 40\%), with a mean age of onset at 42 years +/- 16 (SD). Most of the patients were European Caucasian $(\mathrm{n}=219,91 \%)$, six North Africans and 16 of unknown origin. They all were examined by trained neurologists using the same diagnostic form. They all fulfilled the UKBrain bank diagnostic criteria for "probable" $\mathrm{PD}^{2}$.

Exome sequencing was performed at the ICM IGenSeq core facility or Integragen (Evry, France). Exons were captured using the Roche V.3 or Twist_Refseq $40 \mathrm{Mb}$ kit followed by a massively parallel sequencing on the NextSeq500 or NovaSeq system (Illumina). We excluded genetic variants that did not alter coding sequences and variants with a minor allele frequency $>0.01$ in control subjects in one or more reference databases (The Genome Aggregation Database, GnomAD $\left.{ }^{3}\right)$. Combined Annotation Dependent Depletion $\left(\mathrm{CADD}^{4}\right)$ scores were used to summarize how deleterious amino acid substitutions are to protein function.

No variant fulfilling these criteria was identified, indicating the absence of disease-causing variants in $U Q C R C 1$ in our population. Considering the total number of families with AD PD included in the study (383 in total), the UQCRC1 gene seems very rarely implicated in familial European Caucasian cases. However, the precise frequency of $U Q C R C 1$ variants in the Asian population cannot be precisely evaluated because the number of families with autosomal dominant inheritance among the 669 index cases screened by Lin et $a l^{1}$ is not indicated. In addition, two recent studies including 1647 European and 452 Asian sporadic PD patients respectively did not find any evidence for association of UQCRC1 with Parkinson's disease ${ }^{5,6}$.

As mentioned by the authors, the low frequency of pathogenic variants in UQCRC1 in familial PD suggest that variants in this gene are a rare genetic cause of AD parkinsonism, found, until now, only in the asian population. Their absence in this first large cohort of selected families with AD inheritance (the more likely candidate families for identifying dominant variants) can be due to different factors. First, they could be absent or extremely rare in the Caucasian population. Second, exome analysis did not allow testing for other types of variants such as copy number variants or extragenic regulatory variants that have yet not been described for UQCRC1. Third, UQCRC1 variants may cause a specific syndrome which combines parkinsonism and early onset polyneuropathy, an extremely rare phenotype already described in some specific syndromes ${ }^{7}$ and which was not reported in our cohort. Indeed, Lin et al ${ }^{1}$ provide a detailed description of the polyneuropathy which occurs long before PD symptoms in their large family. In contrast, no overt polyneuropathy was reported in the two remaining $U Q C R C 1$ families but no electrophysiological studies were performed to exclude its presence. 
Therefore, it would be interesting to screen for $U Q C R C 1$ specifically in pedigrees with the very rare phenotype of $\mathrm{AD}$ parkinsonism and polyneuropathy in a follow up study.

1. Lin C-H, Tsai P-I, Lin H-Y, et al. Mitochondrial UQCRC1 mutations cause autosomal dominant parkinsonism with polyneuropathy. Brain J Neurol. 2020;143(11):3352-3373. doi:10.1093/brain/awaa279

2. Hughes AJ, Daniel SE, Kilford L, Lees AJ. Accuracy of clinical diagnosis of idiopathic Parkinson's disease: a clinico-pathological study of 100 cases. J Neurol Neurosurg Psychiatry. 1992;55(3):181-184. doi:10.1136/jnnp.55.3.181

3. Karczewski KJ, Francioli LC, Tiao G, et al. The mutational constraint spectrum quantified from variation in 141,456 humans. Nature. 2020;581(7809):434-443. doi:10.1038/s41586-020-2308-7

4. Rentzsch P, Witten D, Cooper GM, Shendure J, Kircher M. CADD: predicting the deleteriousness of variants throughout the human genome. Nucleic Acids Res. 2019;47(D1):D886-D894. doi:10.1093/nar/gky1016

5. Senkevich K, Bandres-Ciga S, Gan-Or Z, Krohn L, International Parkinson's Disease Genomics Consortium (IPDGC). Lack of evidence for association of UQCRC1 with Parkinson's disease in Europeans. Neurobiol Aging. Published online November 2, 2020. doi:10.1016/j.neurobiolaging.2020.10.030

6. Lin Z-H, Zheng R, Ruan Y, et al. The lack of association between ubiquinol-cytochrome c reductase core protein I (UQCRC1) variants and Parkinson's disease in an eastern Chinese population. CNS Neurosci Ther. 2020;26(9):990-992. doi:10.1111/cns.13436

7. Vital A, Lepreux S, Vital C. Peripheral neuropathy and parkinsonism: a large clinical and pathogenic spectrum. J Peripher Nerv Syst JPNS. 2014;19(4):333-342. doi:10.1111/jns.12099

Data availability statement :

The data that support the findings of this study are available from the corresponding author, TC, upon reasonable request.

Funding information :

Association France Parkinson

Prix Allianz

Competing interests :

The authors declare no competing interests. 